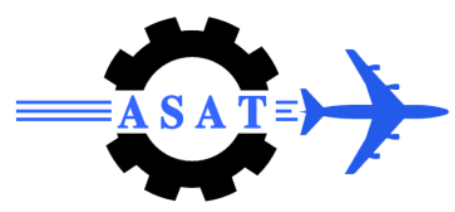

\title{
Object Based Change Detection for Remote Sensing Data
}

\author{
I.H. Khalifa ${ }^{*}$, F. El Tohamy ${ }^{\dagger}$, I.H. Aqabat ${ }^{\star}$
}

\begin{abstract}
Image change detection is an important application of remote sensing technology. It is a process ascertaining the changes of specific features within a certain time interval. This paper presents an object-oriented image change detection methodology to detect the changes and analyze aerial remote sensing data of Sanaa sub-area. Furthermore, the urban growth (sprawl) in the study area is monitored and analyzed. A rule-based classification technique is applied by using fuzzy functions, aiming to extract information of the urban spatial structure. Finally the classification accuracy of the used images was assessed with parameters of overall accuracy, and kappa statistic.
\end{abstract}

Keywords: Remote sensing, Object classification, Object change detection

\section{Introduction}

Remote sensing from air and space provides valuable data for various civilian and military applications. However, to explore the full value of these data, the appropriate information has to be extracted and presented in format that allows efficient decision processes. Change detection is an important process in monitoring and managing natural resources and urban development. Tracking land cover changes using remotely-sensed data contributes to evaluating to what extent human activities impact the environment [1]. Change detection can be done by many methods from which image subtraction, image ratio, and after image classification [2]. In this paper change detection after image classification based on objectoriented is applied. Object Oriented Change detection is the process of identifying differences in the state of an object or phenomenon by observing it at different times [3]. The object-oriented approach can contribute to powerful automatic and semi-automatic analysis for most remote sensing applications [4]. Object-oriented techniques, also, incorporate both spectral and spatial information which leads to identify the land cover types more effectively. Object-oriented techniques are becoming more popular compared to traditional pixel-based image analysis [5].

\section{Study Area and Remote Sensing Data}

\subsection{Study Area}

The study area is a sub-area of Sanaa city, the capital of Yemen, Fig. 1. Sanaa is located at the center of the Yemeni plateau at a height of about 2150 meters above sea level, the western

\footnotetext{
* Professor of Computer Science Faculty of Computers and Information Helwan University, dr_iraky@hotmail.com

Egyptian Armed Forces, Egypt, ftohamy72@yahoo.com

MSc. Student, Faculty of Computers and Information, Helwan University, ibrgmh97@yahoo.com
} 
foothills of the mountain we do, on the (E417930.4, N168997912) and (E419569,N1688983.7). The population of the secretariat of the capital, according to the census results for 2004 is $1,747,834$ people and the population is growing at a rate of $5.55 \%$ per annum. The study area is about $1.62169 \mathrm{~km}^{2}$.

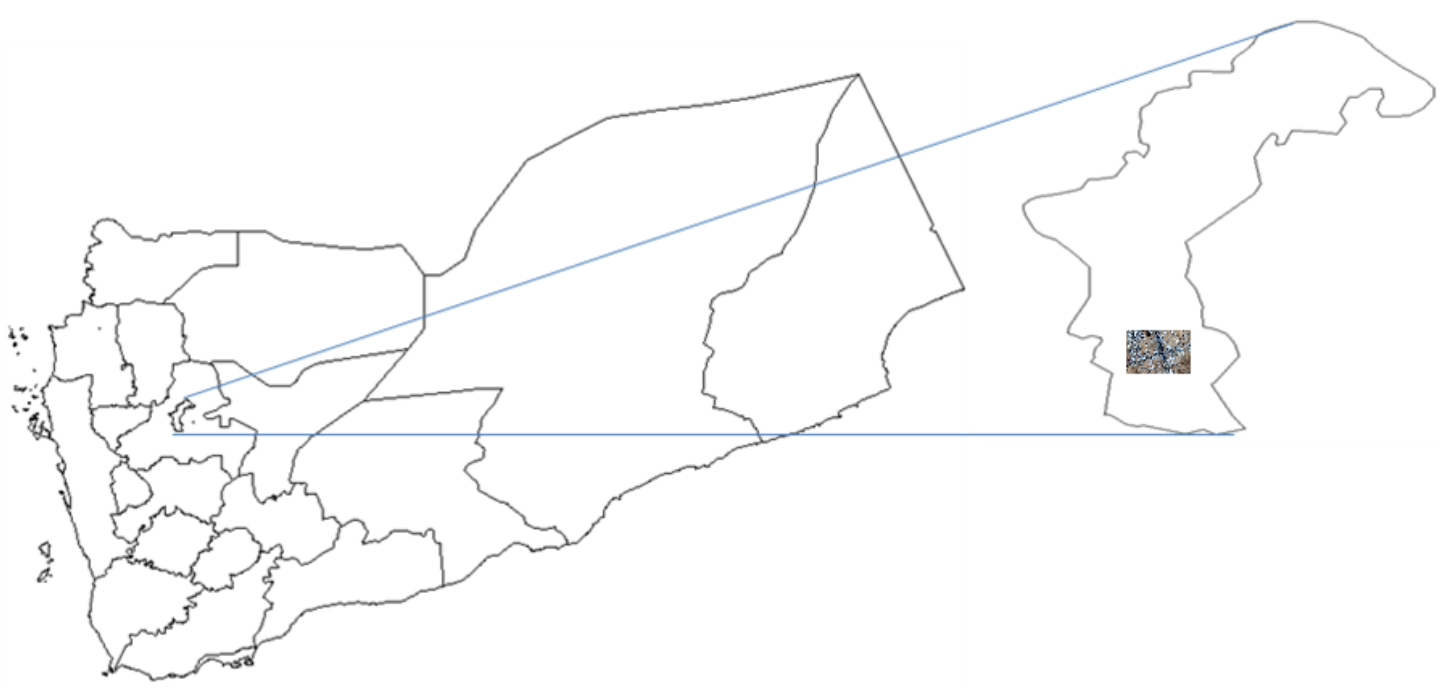

Fig. 1 Location of study area

\subsection{Remote Sensing Data of Study Area}

The remote sensing data, of the study area, used in this paper comprises two aerial images of 1994 (July) and 2003 (July), respectively, Fig. 2a, b. They shall be named image93 and image04 respectively. Image 94 is panchromatic (one band-visible), with resolution of $63 \mathrm{Cm}$, while image 03 is true color ( 3 bands-BGR) with resolution of $60 \mathrm{Cm}$.

\subsection{Pre-Processing of Remote Sensing Data}

Both images used in this study have been already radiometrically corrected. Image 2003 only has been geometrically corrected to UTM projection system (WGS 84). Image to image registration method is used for geometric correction of image1994 (image2003 is used as a reference image). Nearest neighbor method is used to locate the pixel values on the corrected image, this will preserve the pixel values of the original image which is useful for further image classification process.

\section{Object Oriented Image Classification}

The most evident difference between pixels based image classification and object oriented image classification is that, firstly the basic processing units are image objects or segments, not single pixels in object oriented image classification. Secondly, the classifiers in object oriented image classification are soft classifiers that are based on fuzzy logic. Soft classifier use membership to express an object's assignment to a class. The membership value usually lies between 1.0 and 0.0 , where 1.0 expresses a complete assignment to a class and 0.0 expresses absolutely improbability. The degree of membership depends on the degree to which the objects fulfill the class-describing conditions. The advantage of these soft classifiers lies in their possibility to express uncertainties about the classes' descriptions. 


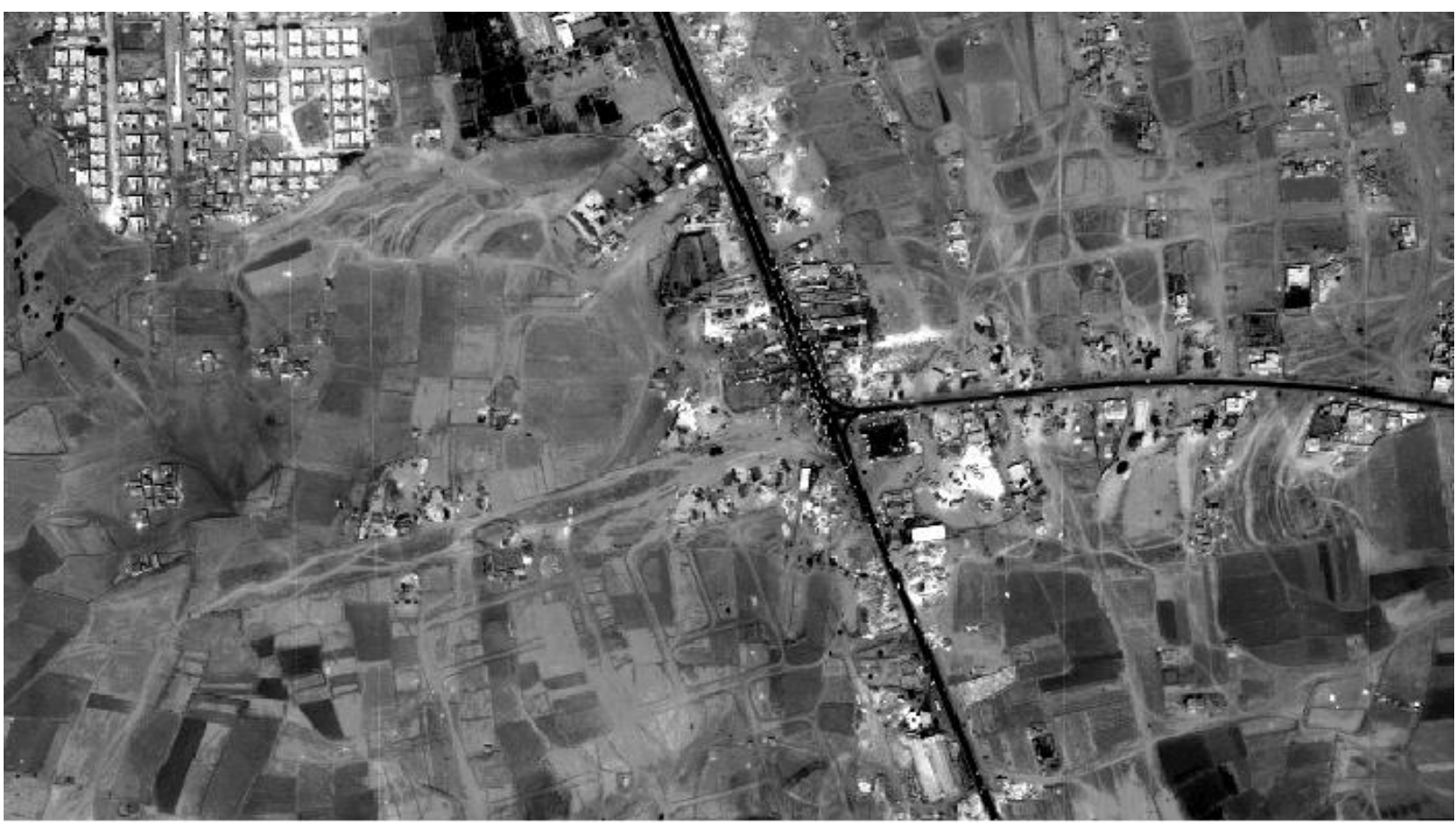

Fig. 2a Aerial pan image (1 band) of south of Sanaa acquired in 1994

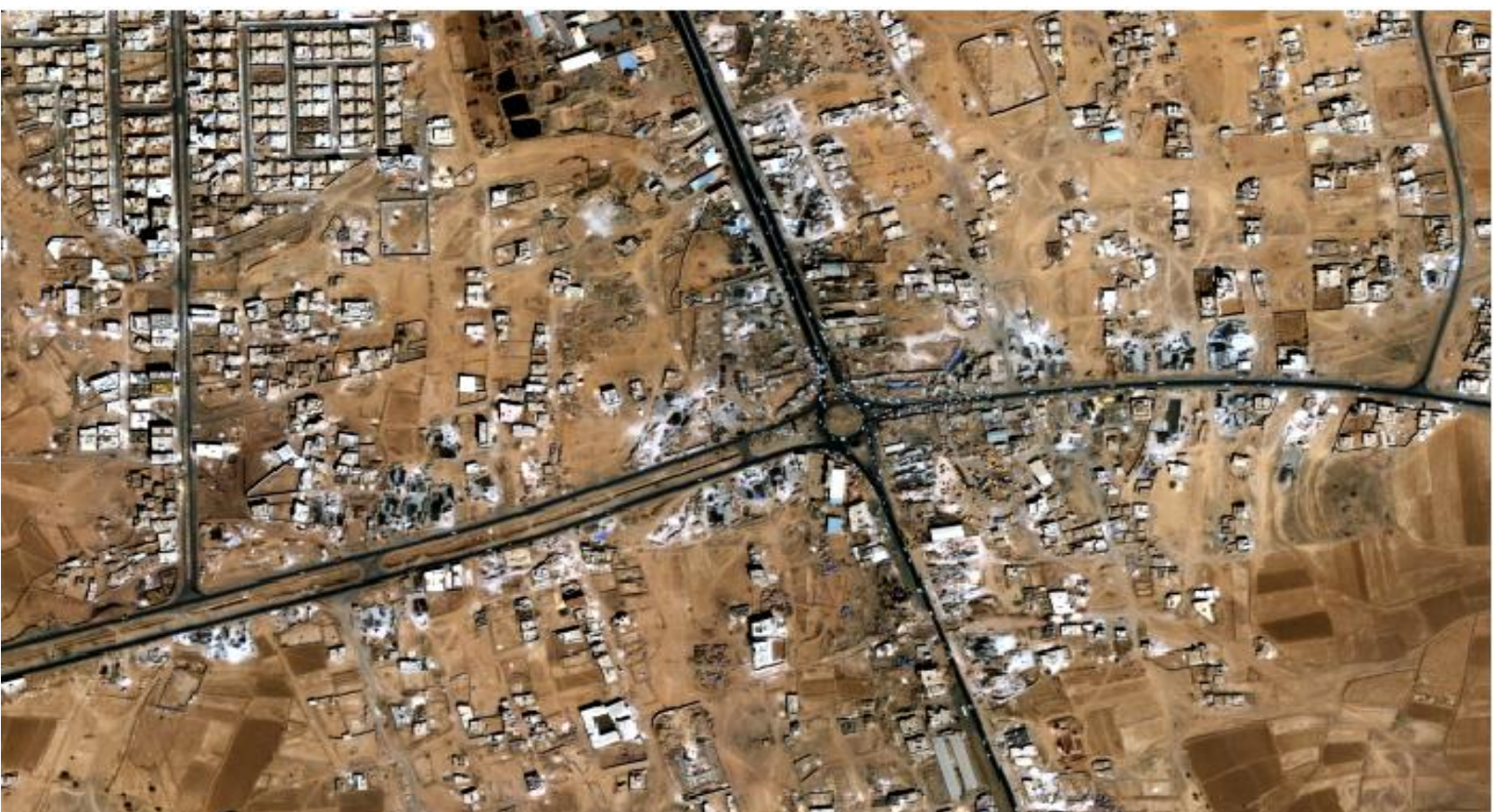

Fig. 2b Aerial true color image (3bands) of south of Sanaa acquired in 2003

The basic processing units in object oriented image classification are objects or pixel clusters, with object oriented approach to analyze images; the initial step is always to form the processing units by image segmentation. The object oriented classification is performed by segmenting the image using region growing algorithm and applying fuzzy classification[6].

\subsection{Fuzzy Based Object Oriented Classification}

In object oriented image analysis the classifier is soft classifier (for example fuzzy system), which uses a degree of membership to express an object's assignment to a class. The membership value usually lies between 1.0 and 0.0 , where 1.0 expresses full membership (a complete assignment) to a class and 0.0 expresses absolutely non-membership. The degree of 
membership depends on the degree to which the objects fulfill the class-describing conditions. The main advantage of this soft classifier lies in their possibility to express uncertainties about the classes' descriptions. It makes it also possible to express each object's membership in more than just one class or the probability of belonging to other classes, but with different degrees of membership. With respect to image understanding these soft classification results are more capable of expressing uncertain human knowledge about the world and thus lead to classification results which are closer to human language, thinking and mind. The result of classification of image94 and image03, using ERDAS, IMAGINE Objective, are given in Fig. 3 and Fig. 4 respectively.

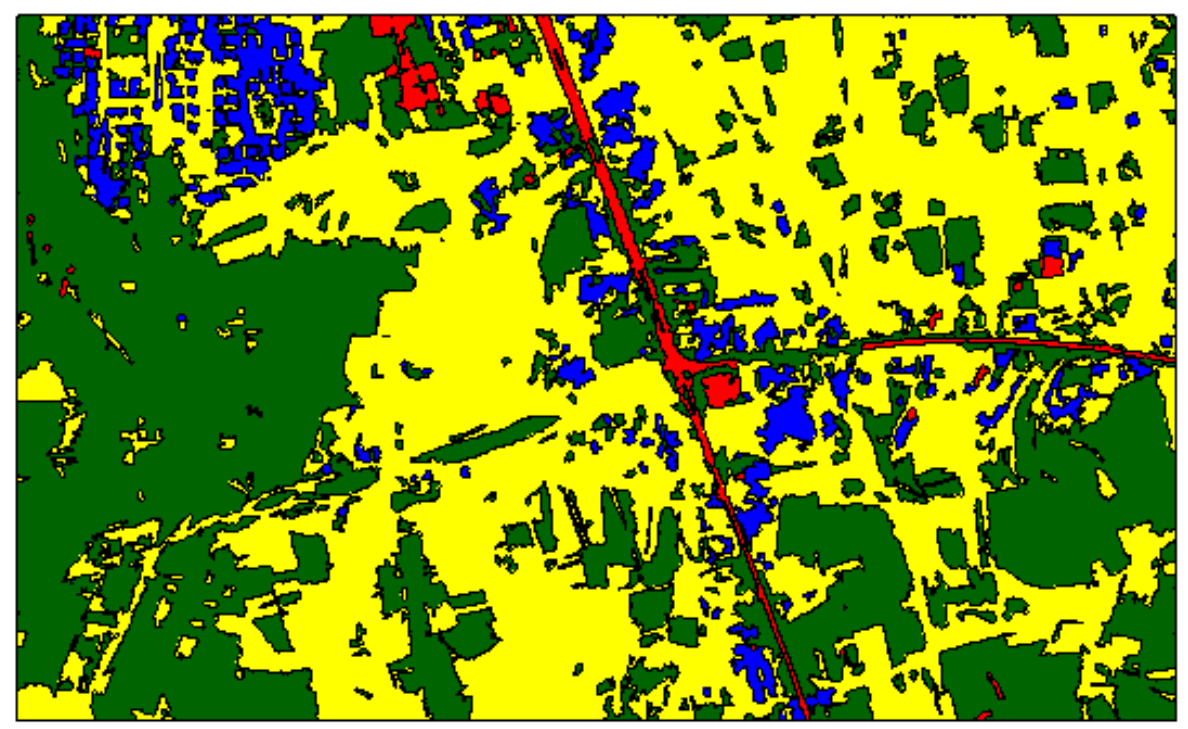

Object Classification 1994

Buildingss

Roads;

Agriculture

Barren Bare

Fig. 3 Object based classification for aerial pan 1 band image 1994

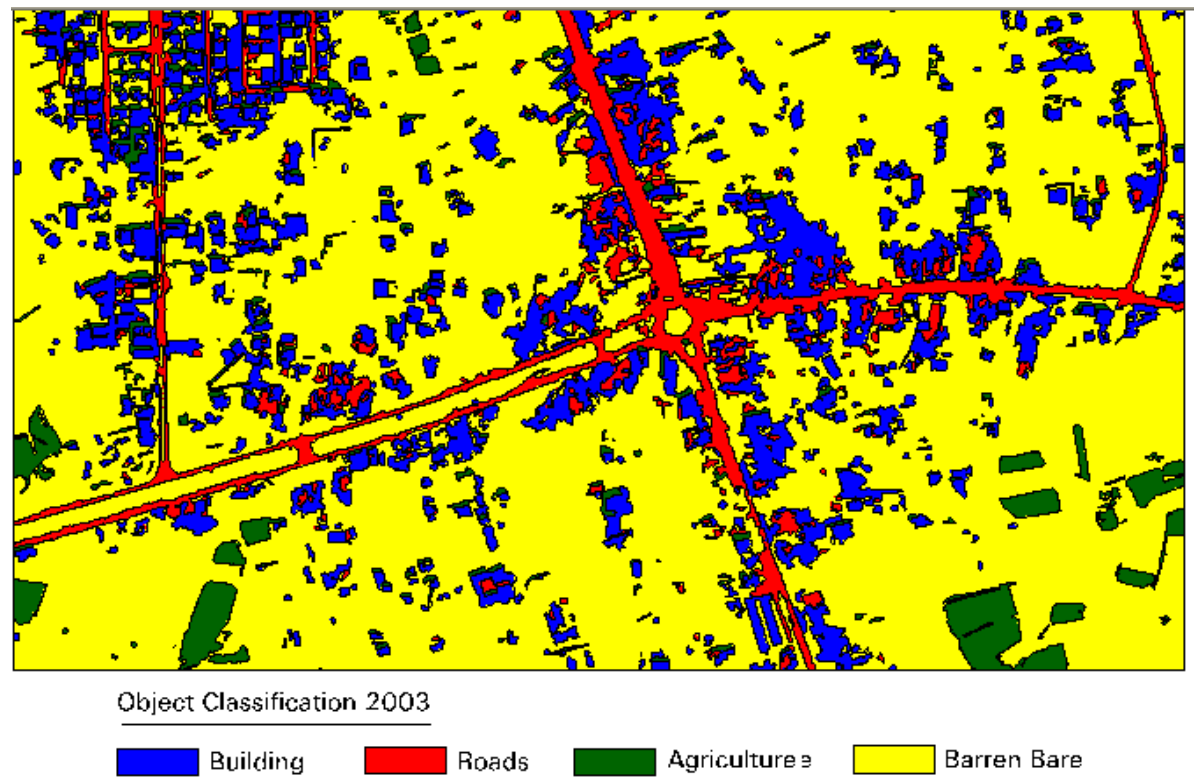

Fig. 4 Object based classification for aerial true color 3 band image 2003 


\subsection{Accuracy Assessment}

The classification accuracy has been assessed using overall accuracy, and kappa statistic. In this context, the "accuracy" means the level of agreement between labels assigned by the classifier and class allocations on the ground user as test data. With error matrix, error of omission and commission can be shown clearly and also several accuracy indexes such as overall accuracy can be assessed. The following is the detailed description about the three accuracy indexes and their calculation methods.

\subsubsection{Overall accuracy}

Overall accuracy is computed by dividing the total number of correctly classified pixels (the sum of the elements along the main diagonal) by the total number of reference pixels. From the error matrix, the overall accuracy can be calculated as the following:

$$
O A=\frac{\sum_{k=1}^{N} a_{k k}}{\sum_{i, \mathrm{k}=1}^{N} a_{k}}=\frac{1}{n} \sum_{k=1}^{N} a_{k k}
$$

Overall accuracy is a very coarse measurement. It gives no information about what classes are classified with good accuracy.

\subsubsection{Kappa coefficient}

Kappa coefficient provides a difference measurement between the observed agreement of two maps and agreement that is contributed by chance alone. A Kappa coefficient of $90 \%$ may be interpreted as $90 \%$ better classification than would be expected by random assignment of classes.

$$
\text { Kappa Statistic } \widehat{K}=\frac{\left(n * \operatorname{SUM}\left(X_{i i}\right)\right)-\operatorname{SUM}\left(X_{i+} * X_{+i}\right)}{n^{2}-\operatorname{SUM}\left(X_{i+} * X_{+i}\right)}
$$

where:

SUM = sum across all rows in matrix

$\mathrm{X}_{\mathrm{i}+} \quad=$ marginal row total (row i)

$\mathrm{X}_{+\mathrm{i}} \quad=$ marginal column total (column $\mathrm{i}$ )

$\mathrm{n}=$ = number of observations takes into account the off-diagonal elements of the contingency matrix (errors of omission and commission).

The accuracy assessment and accuracy statistics of classification result are given in Tables 1 to 4 respectively. The overall classification accuracy $=90.77 \%$ and overall kappa statistics $=0.8761$ of image 94 and the overall classification accuracy $=93.98 \%$ and overall kappa statistics $=0.9197$ of image 03 because image 2003 3-Band and image 1994 1-Band.

Table 1 Error Matrix of 1994 aerial pan Image using stratified random method

\begin{tabular}{l|c|c|c|c|c}
\hline \multirow{2}{*}{ Classified Data } & \multicolumn{5}{|c}{ Referenced Data } \\
\cline { 2 - 6 } & Road & Buildings & Barren Bare & Agriculture & Row Total \\
\hline Road & 13 & 0 & 0 & 2 & 15 \\
\hline Buildings & 0 & 12 & 3 & 0 & 15 \\
\hline Barren Bare & 0 & 0 & 18 & 0 & 18 \\
\hline Agriculture & 0 & 0 & 1 & 16 & 17 \\
\hline Column Total & 13 & 12 & 22 & 18 & 65 \\
\hline
\end{tabular}


Table 2 Accuracy statistics for the classification result of 1994 aerial pan Image using stratified random method

\begin{tabular}{l|c|c|c|c|c|c}
\hline Class Name & $\begin{array}{c}\text { Reference } \\
\text { Totals }\end{array}$ & $\begin{array}{c}\text { Classified } \\
\text { Totals }\end{array}$ & $\begin{array}{c}\text { Number } \\
\text { Correct }\end{array}$ & $\begin{array}{c}\text { Producers } \\
\text { Accuracy }\end{array}$ & $\begin{array}{c}\text { Users } \\
\text { Accuracy }\end{array}$ & Kappa \\
\hline Road & 13 & 15 & 13 & $100.00 \%$ & $86.67 \%$ & 0.8333 \\
\hline Buildings & 12 & 15 & 12 & $100.00 \%$ & $80.00 \%$ & 0.7547 \\
\hline Barren Bare & 22 & 18 & 18 & $81.82 \%$ & $100.00 \%$ & 1.0000 \\
\hline Agriculture & 18 & 17 & 16 & $88.89 \%$ & $94.12 \%$ & 0.9186 \\
\hline Column Total & 65 & 65 & 59 & & & \\
\hline
\end{tabular}

Table 3: Error Matrix of 2003 aerial true color Image using stratified random method

\begin{tabular}{l|c|c|c|c|c}
\hline \multirow{2}{*}{ Classified Data } & \multicolumn{5}{|c}{ Referenced Data } \\
\cline { 2 - 6 } & Road & Buildings & Barren Bare & Agriculture & Row Total \\
\hline Road & 17 & 0 & 0 & 2 & 19 \\
\hline Buildings & 0 & 17 & 3 & 0 & 20 \\
\hline Barren Bare & 0 & 0 & 25 & 0 & 25 \\
\hline Agriculture & 0 & 0 & 0 & 18 & 18 \\
\hline Column Total & 17 & 17 & 28 & 20 & 83 \\
\hline \hline
\end{tabular}

Table 4 Accuracy statistics for the classification result of 2003 aerial true color Image using stratified random method

\begin{tabular}{l|c|c|c|c|c|c}
\hline Class Name & $\begin{array}{c}\text { Reference } \\
\text { Totals }\end{array}$ & $\begin{array}{c}\text { Classified } \\
\text { Totals }\end{array}$ & $\begin{array}{c}\text { Number } \\
\text { Correct }\end{array}$ & $\begin{array}{c}\text { Producers } \\
\text { Accuracy }\end{array}$ & $\begin{array}{c}\text { Users } \\
\text { Accuracy }\end{array}$ & Kappa \\
\hline Road & 17 & 19 & 17 & $100.00 \%$ & $89.47 \%$ & 0.8676 \\
\hline Buildings & 17 & 20 & 17 & $100.00 \%$ & $85.00 \%$ & 0.8114 \\
\hline Barren Bare & 28 & 25 & 25 & $89.29 \%$ & $100.00 \%$ & 1.0000 \\
\hline Agriculture & 20 & 18 & 18 & $90.00 \%$ & $100.00 \%$ & 1.0000 \\
\hline Column Total & 83 & 83 & 78 & & & \\
\hline
\end{tabular}

\section{Object-Oriented Change Detection}

A variety of digital change detection techniques has been developed in the past three decades. Reviews on the most commonly used techniques are given in [3-7]. For the detection of change pixels, several statistical techniques exist, calculating e.g. the spectral or texture pixel values, estimating the change of transformed pixel values or identifying the change of class memberships of the pixels. But when adopted to high-resolution imagery, the results of these pixel-based algorithms are sometimes limited. Especially if small structural changes are to be 
detected, object-oriented procedures seem to be more precise and meaningful. Object-oriented change detection and analysis techniques can in addition estimate the changes of the mean object features (spectral colour, form, etc.), assess the modified relations among neighboring, sub- and super-objects and find out changes regarding the object class memberships. Previous studies implying a combination of pixel- and object based techniques have already demonstrated the advantages of firstly pinpointing the significant change pixels by statistical change detection and subsequently post-classifying the changes by means of a semantic model of change related object features [8].

\section{Change Analysis}

Utilizing the Land Change Analysis Panel in the LCM and Cross-tabulation analysis in the CROSSTAB module [9], we were able to develop additional insights into past LC during: $1994-2003$. The change analysis panel provides graphs of gains/losses and net change by land cover class. The Cross-tabulation analysis provides two functions, which are Crossclassification image and cross tabulation. Cross-classification image shows the location of the changes and non-change areas of the classes in the original images represented by different colors. The legend presents categories of image94 versus image03. (Fig 6) shows crossclassification of classified images between 1994 and 2003. The cross tabulation (Tables 5,6 ,and 7) compares the number of cells in each combination of the classes of image94 to those of a image03 (area in pixels ,\%, area in square meter) respectively . A function to calculate areas of the combinations is available from the software.

In terms of the net change between 1994 and 2003 (Table 8, and Fig 7), the greatest increase were observed in Building with $45.56 \%$ of total area. A small increase was observed in roads with $2.06 \%$ of total area. Losses were evident in agriculture, barren bear with $13.34 \%$, $31.65 \%$ of total area, respectively.

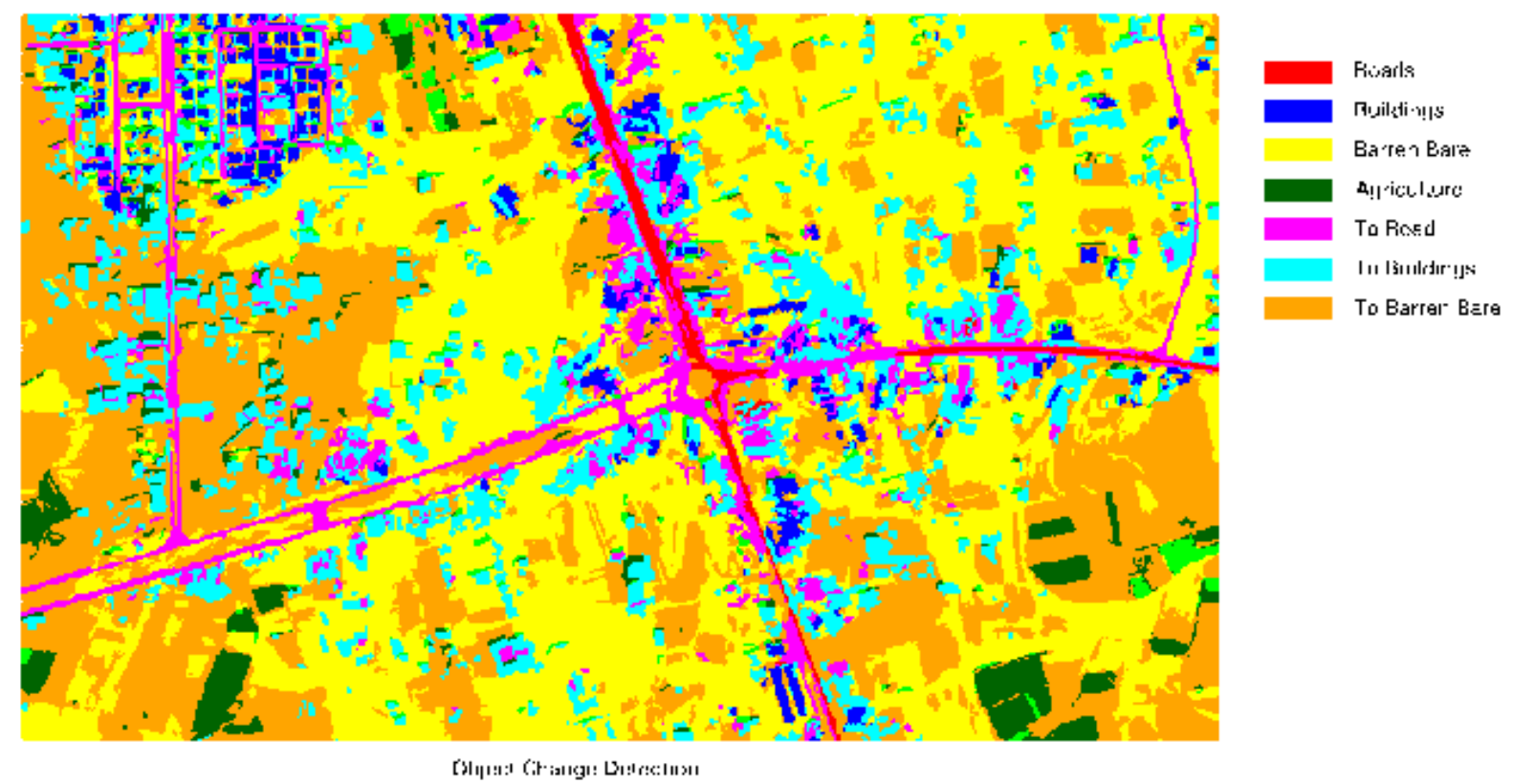

Fig. 5 Object Change Detection 1994- 2003 
Table 5 Cross-tabulation of land cover classes between 1994 and 2003 (area in pixels)

\begin{tabular}{l|c|c|c|c|c|c}
\hline \hline $\begin{array}{c}\text { Classified } \\
\text { Data }\end{array}$ & Unclassified & Road & Buildings & $\begin{array}{c}\text { Barren } \\
\text { Bare }\end{array}$ & Agriculture & $\begin{array}{c}\text { Pixel } \\
\text { Count }\end{array}$ \\
\hline Unclassified & 13 & 0 & 23 & 10 & 3 & 49 \\
\hline Road & 3 & 38161 & 27911 & 2616 & 16964 & 85655 \\
\hline Buildings & 22 & 6934 & 249186 & 3350 & 10389 & 269881 \\
\hline Barren Bare & 70 & 46238 & 1263309 & 909278 & 158777 & 2377672 \\
\hline Agriculture & 33 & 4521 & 800673 & 527510 & 437154 & 1810651 \\
\hline
\end{tabular}

Table 6 Cross-tabulation of land cover classes between 1994 and 2003 (\%)

\begin{tabular}{l|c|c|c|c|c|c}
\hline $\begin{array}{c}\text { Classified } \\
\text { Data }\end{array}$ & $\begin{array}{c}\text { Unclassified } \\
\%\end{array}$ & $\begin{array}{c}\text { Road } \\
\%\end{array}$ & $\begin{array}{c}\text { Buildings } \\
\%\end{array}$ & $\begin{array}{c}\text { Barren } \\
\text { Bare } \%\end{array}$ & $\begin{array}{c}\text { Agriculture } \\
\%\end{array}$ & $\%$ \\
\hline Unclassified & 26.53 & 0.00 & 46.94 & 20.41 & 6.12 & 100.00 \\
\hline Road & 0.00 & 44.55 & 32.59 & 3.05 & 19.81 & 100.00 \\
\hline Buildings & 0.01 & 2.57 & 92.33 & 1.24 & 3.85 & 100.00 \\
\hline Barren Bare & 0.00 & 1.94 & 53.13 & 38.24 & 0.022 & 100.00 \\
\hline Agriculture & 0.00 & 2.50 & 44.22 & 29.13 & 24.14 & 100.00 \\
\hline \hline
\end{tabular}

Table 7 Cross-tabulation of land cover classes between 1994 and 2003 (Area in square meter)

\begin{tabular}{l|c|c|c|c|c}
\hline \hline $\begin{array}{c}\text { Classified } \\
\text { Data }\end{array}$ & Road & Buildings & Barren Bare & Agriculture & $\begin{array}{c}\text { Square } \\
\text { Meters }\end{array}$ \\
\hline \hline Road & 12949.94 & 10359.95 & 0 & 5179.97 & 28489.86 \\
\hline Buildings & 2589.98 & 90649,58 & 0 & 2589.98 & 95829.56 \\
\hline Barren Bare & 15539.92 & 455837.9 & 327338.5 & 56979.74 & 854696.08 \\
\hline Agriculture & 15539.92 & 287488.68 & 189069.13 & 157989.27 & 652677 \\
\hline Column Total & 33669.82 & 743326.58 & 516407.63 & 217558.99 & 1631692.5 \\
\hline
\end{tabular}

Table 8 Changes of land cover classes between 1994 and 2003

(Area in square meter and \%)

\begin{tabular}{l|c|c|c|c|c}
\hline \hline Classified Data & $\begin{array}{c}\text { Year 1994 } \\
\mathrm{M}^{\wedge} 2\end{array}$ & $\begin{array}{c}\text { Year 2003 } \\
\%\end{array}$ & $\begin{array}{c}\text { Year 2003 } \\
\mathrm{M}^{\wedge} 2\end{array}$ & $\begin{array}{c}\text { Year } \\
2003 \%\end{array}$ & Change \\
\hline Road & 28489.86 & 1.75 & 33669.82 & 2.06 & 5179.96 \\
\hline Buildings & 95829.56 & 5.87 & 743326.58 & 45.56 & 647497.02 \\
\hline Barren Bare & 854696.08 & 52.38 & 516407.63 & 31.65 & -338288.45 \\
\hline Agriculture & 652677 & 40 & 217558.99 & 13.34 & -435118.01 \\
\hline
\end{tabular}




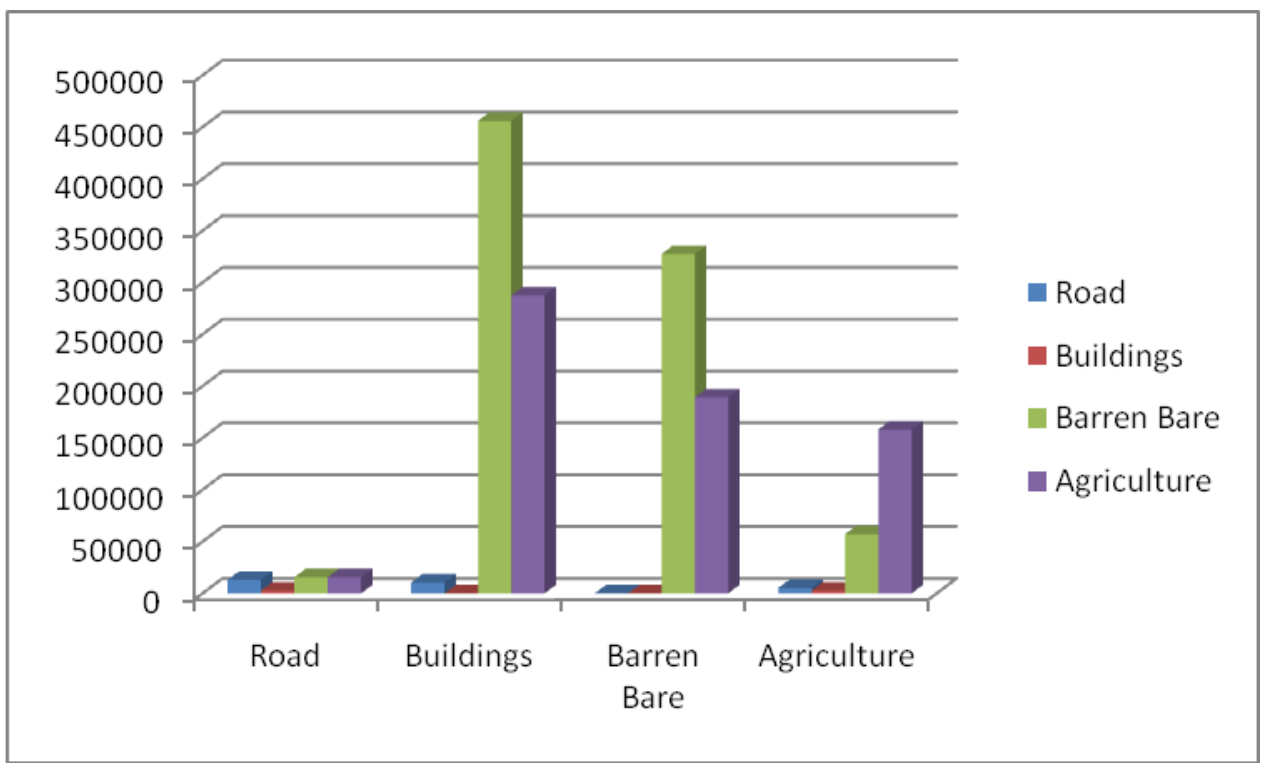

Fig 6 Cross-tabulation of land cover classes between 1994 and 2003 (Area in square meter)

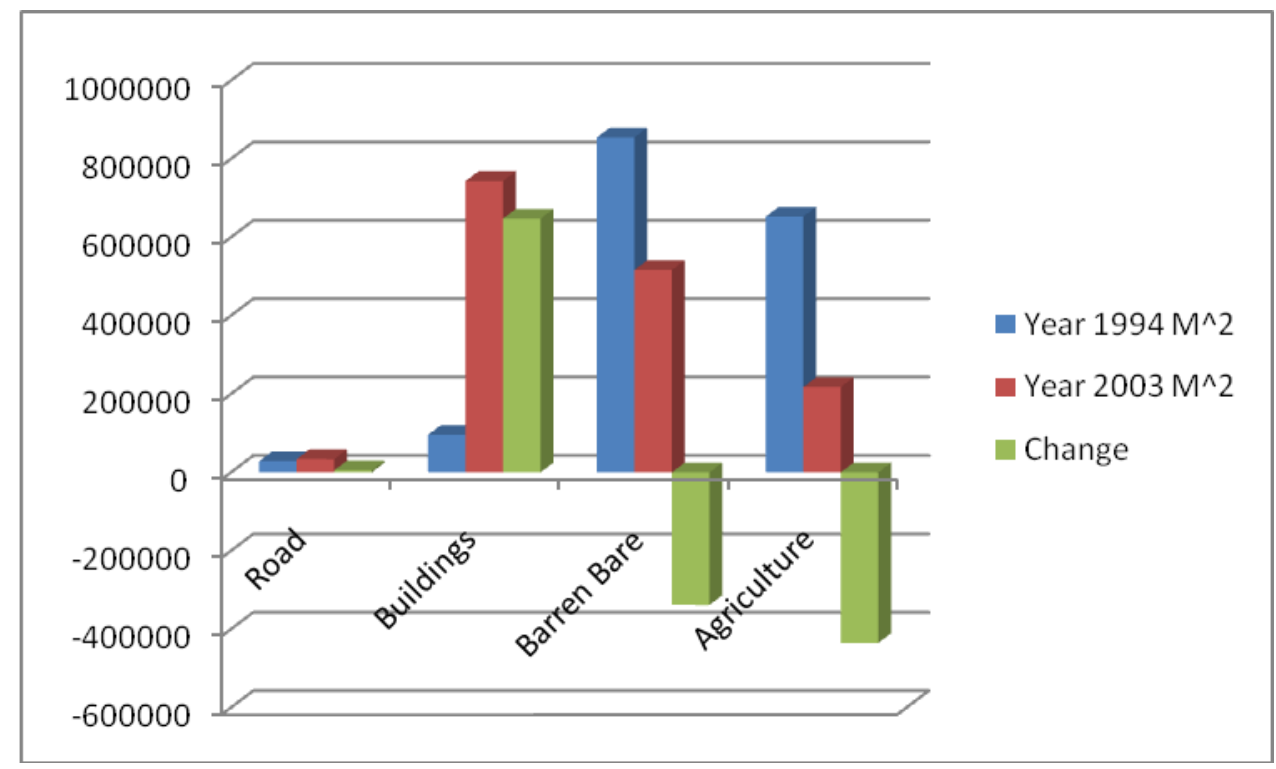

Fig. 7 Changes of land cover classes between 1994 and 2003 (Area in square meter)

\section{Conclusions}

The aim of this paper was to demonstrate the object oriented analysis of aerial images for an effective change detection. The structure of objects and the available number of features allowed the accurate classification of the very high resolution image data. There are numerous ways and methods to handle objects for the efficient identification of changes. Moreover with the advantage of determining the exact "from-to" change, a GIS post classification process can be omitted. The paper was regarded as an intriguing approach to monitor land cover changes of an area with no any previous spatial record. The results confirmed the expanding tension of the city of Sanaa, as illustrated by the elimination of the open air areas and their transformation to built-up areas (impervious). The analysis, the structure, the classification and generally all the information related to the objects can be organized and managed in a GIS database. In this way urban growth prediction and land use studies can be accomplished effectively. 


\section{References}

[1] Sophie Bontemps, "An object-based change detection method accounting for temporal dependences in time series with medium to coarse spatial resolution", Remote Sensing of Environment, 2008, p3181-3191

[2] Benz, U.C., Hoffmann, P., Willhauck, G., Lingenfelder, I. and Heynen,M., "Multiresolution, object-oriented fuzzy analysis of remote sensing data for GIS-ready information", ISPRS Journal of Photogrammetry \& Remote sensing, 2004, Vol 58, 239258 ,

[3] Singh, A. "Digital change detection techniques using remotely sensed Data". International Journal of Remote Sensing, 1989, 10, 989-1003.

[4] Ursula C. Benz, "Multi-resolution, object-oriented fuzzy analysis of remote sensing data for GIS-ready information Ursula C"., ISPRS Journal of Photogrammetry \& Remote Sensing 58 (2004) 239- 258

[5] Ruvimbo Gamanya , "Object-oriented change detection for the city of Harare, Zimbabwe", Expert Systems with Applications , 2009 , 36 571-588

[6] ERDAS 2010 , Inc. IMAGINE Objective Users Guide (January, 2009). Norcross, GA.

[7] D. Lu, P. Mausel, E. Brondizio, and E. Moran, "Change detection techniques", International Journal of Remote Sensing, 2004 , 25(12): 2365-2407.

[8] I. Niemeyer, S. Nussbaum, and M.J. Canty, "Automation of Change Detection Procedures for Nuclear Safeguards-Related Monitoring Purposes", Proc. of the 25th IEEE International Geoscience and Remote Sensing Symposium, IGARSS'05, Seoul, 25-29 July 2005 (CD-Rom).

[9] ERDAS 2010 Incorporated. ERDAS Field Guide 4th Edition. Atlanta, USA, ERDAS Inc., 2009. 